\title{
Efecto bactericida del láser de diodo en periodoncia
}

\author{
CACCIANIGA G* \\ URSO E** \\ MONGUZZI R* \\ GALLO K** \\ REY G***
}

\author{
Caccianiga G, Urso E, Monguzzi R, Gallo K, Rey G. Efecto bactericida \\ del láser de diodo en periodoncia. Av Periodon Implantol. 2007; 19, \\ 1: 131-139.
}

\begin{abstract}
RESUIMEN
El láser en odontología, gracias a su capacidad antibacteriana, hemostática y de menor sintomatología operatoria, encuentra un amplio campo de aplicación en el ámbito de la terapia periodontal.

En este estudio ha sido probada la eficacia de un protocolo que prevé la utilización asociada de irradiación láser y de agua oxigenada con el fin de reducir a carga bacteriana de cepas comúnmente presentes en las bolsas periodontales activas y resistentes a la acción bactericida de solamente la irradiación láser como la Prevotella intermedia, Fusobacterium nucleatum y Peptostreptococcus micron.
\end{abstract}

La metodología de laboratorio preveía el siguiente protocolo: cada una de las suspensiones bacterianas ha sido expuesta al agua oxigenada a una concentración del 3\% y ha sido irradiada con láser por 10, 15 o 20 segundos utilizando tubos estériles Eppendorf de 1,5 ml.

Los resultados confirman la mayor eficacia bactericida de la acción combinada de agua oxigenada y láser. Los cultivos microbiológicos efectuados revelan como, no obstante el efecto bactericida, el láser tiene una escasa acción sobre las cepas bacterianas testadas si no es asociado al agua oxigenada. En particular, en el caso de la Prevotela intermedia y del Fusobacterium nucleatum, la utilización de agua oxigenada al 3\% solamente ha dado resultado mejores respecto a solamente el láser, mientras que la asociación de los dos tratamientos ha dado siempre óptimos resultados. En el caso del Peptostreptococcus micron, la utilización de agua oxigenada y el láser separadamente han dado una escasa disminución de la cuenta bacteriana mientras que la asociación de los tratamientos ha potenciado la acción bactericida.

\section{PALABRAS CLAVE}

Láser de diodo, bacterias, peróxido de hidrógeno.

Fecha de recepción: Febrero 2007.

Aceptado para publicación: Marzo 2007.

* Università degli Studi « Milano Bicocca », Clínica Odontológica. Director: Prof. Marco Baldoni.

** Doctorado de Investigación en Periodontología Experimental. Università degli Studi «Milano Bicocca», Clínica Odontológica.

*** Fundador del I.M.L.A. (International Medical Láser Academy). 


\section{INTRODUCCIÓN}

Debido a su capacidad antibacteriana, hemostática y de menor sintomatología operatoria, el láser encuentra un vasto campo de aplicación en el ámbito de la terapia periodontal.

El término láser es el acrónimo de Light Amplification by Stimulated of Radiation (amplificación de la luz por emisión estimulada de radiación) y los varios tipos de láser se distinguen sobre la base del material ópticamente estimulado. En particular, los láser de diodo más comúnmente utilizados son los láser a arseniuro de galio y aluminio que emiten una longitud de onda de $810 \mu \mathrm{m}$.

La eficacia bactericida del láser ha sido demostrada por varios estudios. Sin embargo, después del tratamiento láser asistido, el análisis de cultivos microbiológicos ha evidenciado la presencia de microorganismos tales como Prevotella intermedia, Fusobacterium nucleatum y Peptostreptococcus micron, comúnmente presentes en las bolsas periodontales y por lo tanto con resistencias diferentes al efecto láser.

Para potenciar el efecto del láser el Dr. Rey ha redactado un protocolo operativo que incluye, además del tratamiento láser asociado, las maniobras de scaling y root planing, el empleo de agua oxigenada, potente antibacteriano activo en bacterias gram+, gram-, esporas y virus, pero que sola no tiene actividad sobre las bacterias mencionadas precedentemente.

El protocolo establece:

1. Eliminación del tártaro con un equipo de ultrasonido con anestesia local hasta el fondo de la bolsa periodontal bajo irrigación con substancias a base de povidona iodada.

2. Pulido de la superficie de la raíz con un chorro de bicarbonato, necesario para detoxificar el cemento de la raíz y abrir los túbulos dentinales (que se vuelven accesibles a la acción del láser).

3. Irrigación de las bolsas periodontales con agua oxigenada a 10 vol.

4. Irradiación láser del epitelio y del fondo de la bolsa periodontal con movimientos rápidos en contacto con el tejido.

5. Irradiación láser del cemento de la raíz con movimientos lentos a aproximadamente $1 \mu \mathrm{m}$ de distancia de la superficie de la raíz.

\section{OBJETIVO DEL TRABAJO}

El objetivo del presente estudio es el de testar la eficiencia bactericida del protocolo elaborado por el Dr. Rey que establece el empleo asociado de irradiación láser y de agua oxigenada a una concentración del 3\% con el fin de disminuir la carga bacteriana de cepas comúnmente presentes en las bolsas periodontales activas. En particular se ha querido testar el empleo del láser de diodo Oralia $810 \mu \mathrm{m}$ con varios protocolos operativos que necesitan el empleo de distintas potencias y fibras de distintos diámetros.

El objetivo de la investigación láser ha sido principalmente el de evaluar el efecto fotodinámico (fotoquímico) evitando posiblemente el efecto fotoablativo y el efecto térmico.

El estudio ha tomado en examen 3 cepas bacterianas:

- Prevotella intermedia.

- Peptostreptococcus micron.

- Fusobacterium nucleatum.

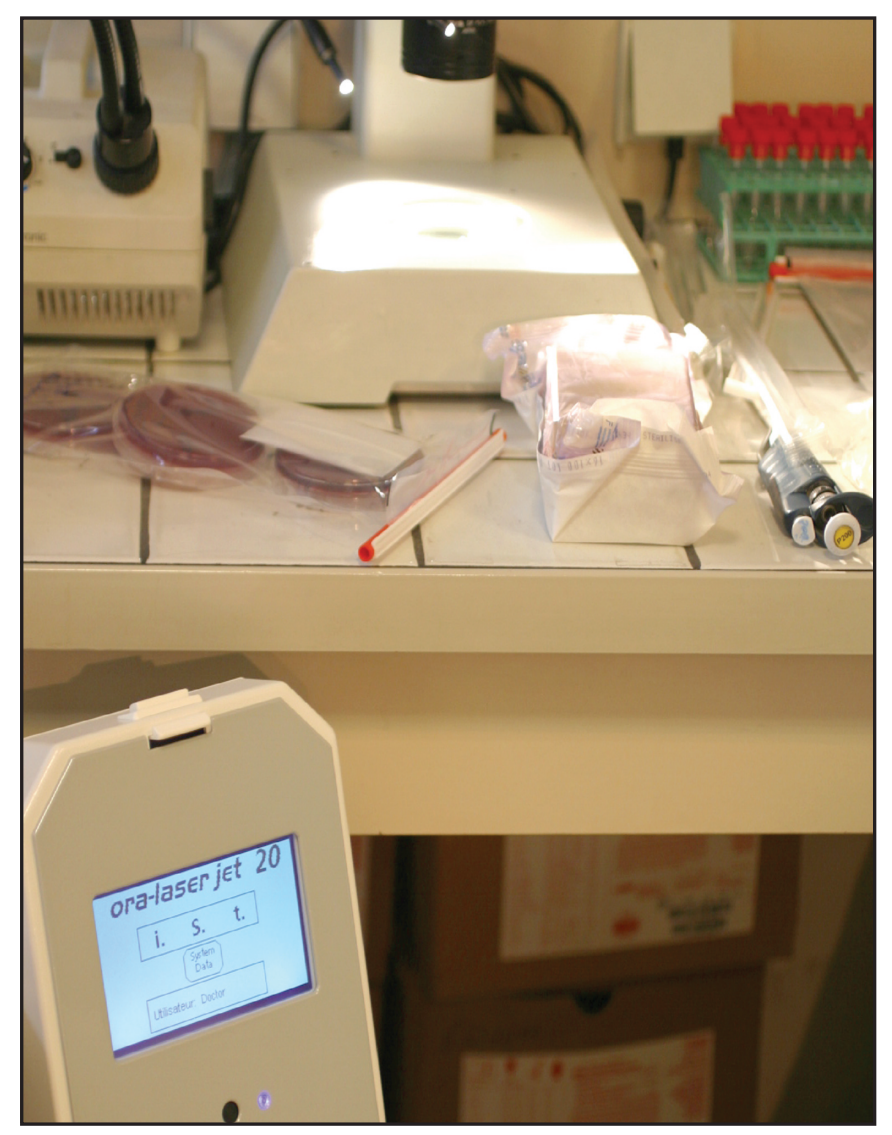

Fig. 1: Láser de diodo Oralia $810 \mu \mathrm{m}$. 


\section{MATERIALES Y MÉTODO}

Los estudios han sido efectuados simulando lo más posible las condiciones de empleo clínico en vivo:

1. Irradiación láser por 10 segundos partiendo del fondo del tubo:

a) Movimiento vertical por 5 segundos.

b) Movimiento rotatorio por 5 segundos.

2. Lavado con peróxido de hidrógeno al 3\%:
a) Volumen igual a 1/3 de la solución inicial

b) Tiempo de contacto de 3 minutos.

3. Comparación del aumento de la temperatura de los distintos test.

\section{TEST}

Han sido utilizados 10 tubos numerados del 1 al 10 con un cultivo conteniendo Prevotella intermedia, Peptostreptococco micron e Fusobacterium nucleatum.

Cada una de las suspensiones bacterianas, expuesta o no al agua oxigenada, ha sido irradiada con el láser, utilizando tubos estériles "Eppendorf" de 1,5 ml. Fueron utilizados otros 10 cultivos iniciales como control.

- Tubo 1: - Tubo de estudio.

- Un cultivo final fue realizado al fin de la experiencia.

- Tubo 2: - Lavados de $\mathrm{H}_{2} \mathrm{O}_{2}-10$ vol.

Los tubos 3 y 4 fueron utilizados siguiendo el programa de descontaminación aconsejado por el fabricante.

- Tubo 3: • Sólo irradiación láser por 5 segundos.

- Irradiación continua -1W- fibra de $400 \mu \mathrm{m}$.

- Se nota el inmediato aumento de la temperatura.

- Tubo 4: • Sólo irradiación láser por 10 segundos

- Irradiación continua -1W- fibra de $600 \mu \mathrm{m}$.

- Se nota el inmediato aumento de la temperatura.

El tubo 5 ha sido utilizado siguiendo el mismo programa del tubo 6 con la finalidad de comparar la eficiencia con o sin peróxido de hidrógeno.

- Tubo 5: • Sólo irradiación láser -programa GR4 por 10 segundos.

- GR4=2,5W-1,2J-50Hz (1/1)- fibra $600 \mu \mathrm{m}$
- Se nota el inmediato aumento de la temperatura.

Los tubos 6, 7, 8, 9 y 10 fueron utilizados siguiendo el protocolo del Dr. Rey (efecto fotoquímico del láser con peróxido de hidrógeno).

- Tubo 6: • Láser $+1 / 3 \mathrm{H}_{2} \mathrm{O}_{2} 10$ vol.

- Programa láser GR4=2,5W-1,2J-50Hz $(1 / 1)$ - fibra $600 \mu \mathrm{m}$ por 10 segundos.

- Tubo 7: • Láser $+1 / 3 \mathrm{H}_{2} \mathrm{O}_{2} 10$ vol.

- Programa láser GR3=2W-1J-50Hz (1/1) fibra $600 \mu \mathrm{m}$ por 10 segundos.

- Tubo 8: • Láser $+1 / 3 \mathrm{H}_{2} \mathrm{O}_{2} 10$ vol.

- Programa láser GR2 = $1 \mathrm{~W}-0,5 \mathrm{~J}-50 \mathrm{~Hz}$ $(1 / 1)$ - fibra $600 \mu \mathrm{m}$ por 15 segundos.

- Tubo 9: - Láser + 1/3 $\mathrm{H}_{2} \mathrm{O}_{2} 10$ vol.

- Programa láser GR $1=0,6 \mathrm{~W}-0,3 \mathrm{~J}-50 \mathrm{~Hz}$ $(1 / 1)$ - fibra $400 \mu \mathrm{m}$ por 20 segundos.

- Tubo 10: Láser + 1/3 $\mathrm{H}_{2} \mathrm{O}_{2} 10$ vol.

- Programa láser GR5=4W-2J-500Hz (1/1) fibra $600 \mu \mathrm{m}$ por 15 segundos.

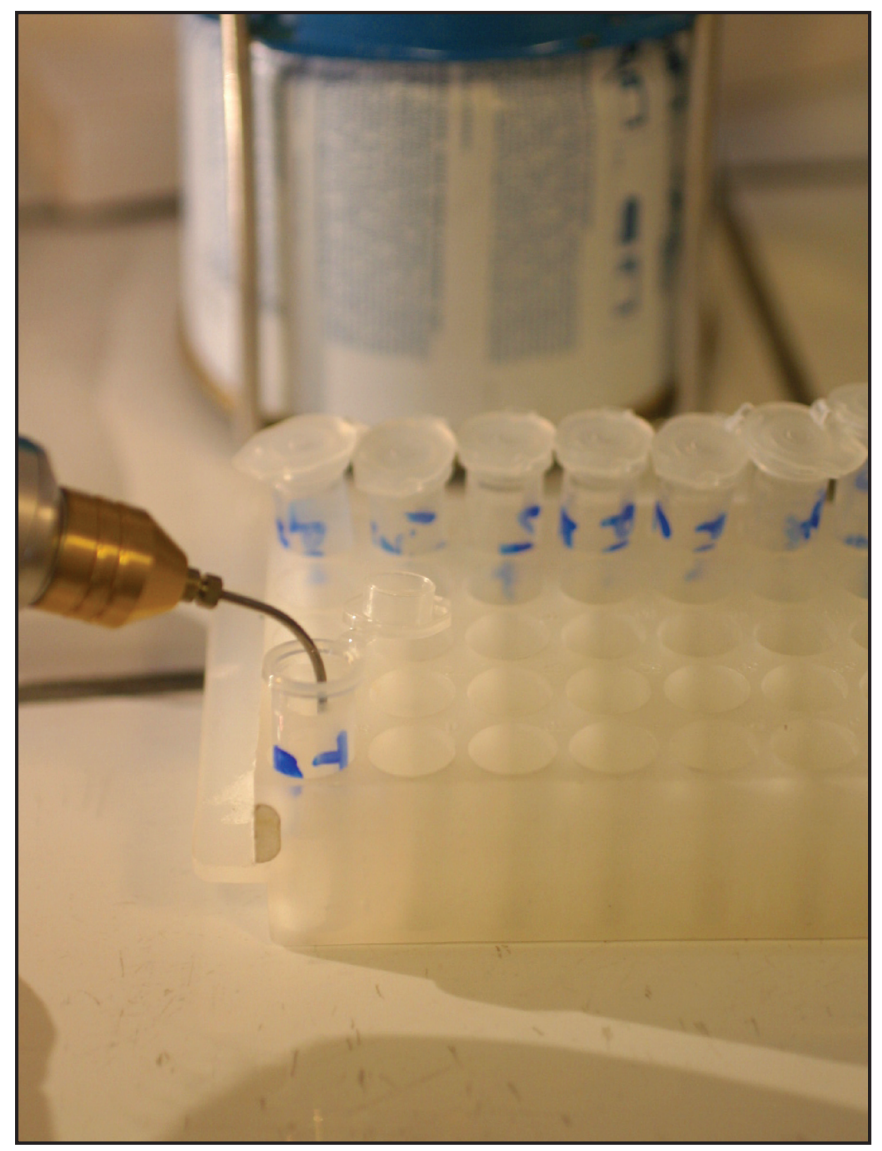

Fig.2. 


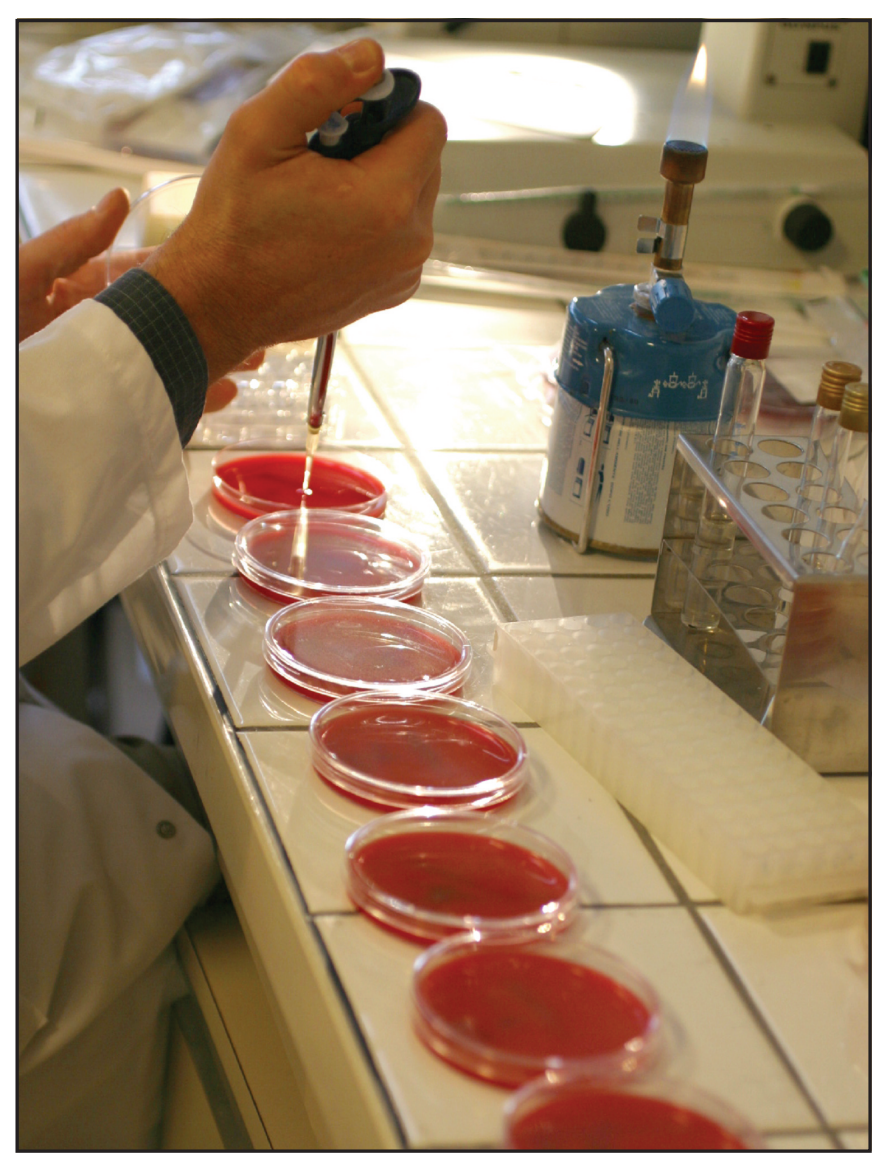

Fig.3.

\section{RESULTADOS}

El empleo exclusivo del $\mathrm{H}_{2} \mathrm{O}_{2}$ en concentración del 3\% ha llevado a una reducción de las colonias bacterianas de $10^{-3}$ igual al $99,95 \%$ en el caso del fusobacetrium nucleatum, de $10^{-1}$ igual al $90 \%$ en el caso del Peptostreptococcus micron y a una reducción del $10^{-5}$ igual al 99,999\% en el caso de la Prevotella intermedia; el empleo exclusivo de la irradiación láser por 10 segundos, sea a la potencia de $1 \mathrm{~W}$ que a $2,5 \mathrm{~W}$, no ha sido eficaz en reducir el número de colonias bacterianas en el caso del Fusobacterium nucleatum, mientras que el empleo de la irradiación láser asociada con el $\mathrm{H}_{2} \mathrm{O}_{2}$ ha producido una notable disminución de las mismas; en particular el empleo de la fibra de $400 \mu \mathrm{m}$ por 20 segundos a una potencia de $0,6 \mathrm{~W}-0,3 \mathrm{~J}-50 \mathrm{~Hz}$ y la fibra de $600 \mu \mathrm{m}$ por 15 segundos con una regulación de $4 \mathrm{~W}-2 \mathrm{~J}-500 \mathrm{~Hz}$, asociados al $\mathrm{H}_{2} \mathrm{O}_{2}$ han llevado a una reducción de 10-6 igual a casi el 100\% de las colonias bacterianas. Muy interesante es la comparación entre las pruebas de los tubos 5 y 6 ; el tubo 5 ha sido utilizado siguiendo el mismo programa del tubo 6 con la finalidad de comparar la eficacia de la irradiación láser con o sin peróxido de hidrógeno, los resultados muestran la ineficacia de la sola irradiación láser, mientras que en el caso de la asociación de los dos tratamientos muestran una reducción de $10^{-5}$ igual a 99,999\% de las colonias.

En las colonias bacterianas de Peptostreptococcus micron el empleo exclusivo de la irradiación láser por 10 segundos, sea a la potencia de $1 \mathrm{~W}$ que a $2,5 \mathrm{~W}$, no ha sido eficaz en reducir el número de colonias bacterianas, mientras que el empleo de la irradiación láser asociada al $\mathrm{H}_{2} \mathrm{O}_{2}$ ha mostrado una disminución de las mismas de $10^{-2}$ en los casos de los tubos 6 (2,5W-1,2J$50 \mathrm{~Hz}(1 / 1)$ - fibra $600 \mu \mathrm{m}), 7$ (2W-1J-50Hz (1/1) - fibra $600 \mu \mathrm{m}), 8(1 \mathrm{~W}-0,5 \mathrm{~J}-50 \mathrm{~Hz}(1 / 1)$ - fibra $600 \mu \mathrm{m})$ e 9 $(0,6 \mathrm{~W}-0,3 \mathrm{~J}-50 \mathrm{~Hz}(1 / 1)$ - fibra $400 \mu \mathrm{m})$ y una reducción de $10^{-3}$, o sea del $99,95 \%$ en el caso del tubo 10 (4W2J-500Hz (1/1) - fibra $600 \mu \mathrm{m})$. También en este caso la comparación entre los tubos 5 y 6 al final de la prueba muestra como utilizando la misma regulación del láser los resultados son mucho mejores en el caso de la asociación con el $\mathrm{H}_{2} \mathrm{O}_{2}$.

La irradiación láser por 10 segundos con regulación 1 $\mathrm{W}-1 \mathrm{~J}$ sea con la fibra de $400 \mu \mathrm{m}$ que con la de $600 \mu \mathrm{m}$ no ha llevado a una reducción significativa de las colonias bacterianas en el caso de la Prevotella intermedia, mientras que el empleo de la fibra de $600 \mu \mathrm{m}$ con la regulación igual a $2.5 \mathrm{~W}-1.2 \mathrm{~J}-50 \mathrm{~Hz}$ ha llevado a una reducción de $10^{-1}$ igual al $90 \%$ de las colonias bacterianas. El empleo del láser con distintas regulaciones asociado con el $\mathrm{H}_{2} \mathrm{O}_{2}$ ha dado en las distintas pruebas una disminución de las colonias bacterianas de $10^{-6}$ igual a casi el $100 \%$.

Los resultados de los diferentes test han sido reportados en las tablas de 1 a 3.

\section{DISCUSIÓN}

En el caso del fusobacetrium nucleatum y de la Prevotella intermedia los análisis microbiológicos han revelado como el empleo exclusivo de agua oxigenada ha dado resultados mejores que la sola exposición a la irradiación láser. En cambio el empleo de los dos tratamientos asociados ha llevado a una marcada disminución de las colonias bacterianas.

En el caso del Peptostreptococcus micron el empleo exclusivo del tratamiento láser no ha producido ninguna reducción apreciable de las colonias bacterianas, mientras que el empleo de agua oxigenada ha 


\section{TABLA 1.- TEST EFECTO BACTERICIDA LÁSER DE DIODO ORALIA $810 \mu \mathrm{m}$ SOBRE FUSOBACTERIUM NUCLEATUM}

\begin{tabular}{|c|c|c|c|c|c|c|}
\hline Tubo & $\begin{array}{l}\text { Cultivo } \\
\text { inicial }\end{array}$ & $\begin{array}{c}\mathrm{H}_{2} \mathrm{O}_{2} \\
\mathbf{3 \%}\end{array}$ & $\begin{array}{c}\text { Esposición } \\
\text { láser de diodo } \\
810 \mu \mathrm{m}\end{array}$ & $\begin{array}{c}\text { Regulación } \\
\text { láser }\end{array}$ & $\begin{array}{c}\text { Tiempos } \\
\text { totales }\end{array}$ & $\begin{array}{c}\text { Cultivo } \\
\text { final }\end{array}$ \\
\hline 1 & Pura & No & No & $\begin{array}{c}\text { Tubo de estudio } \\
\text { cultivo fin de la } \\
\text { experiencia }\end{array}$ & $40 \mathrm{~min}$ & Pura \\
\hline \multicolumn{7}{|c|}{ El tubo 2 ha sido adicionado con 1/3 de peróxido de hidrógeno sin irradiación láser. } \\
\hline 2 & Pura & $3 \min +1 / 3$ & No & & $3 \mathrm{~min}$ & $10^{-3}$ \\
\hline \multicolumn{7}{|c|}{ Los tubos 3, 4 y 5 fueron expuestos a distintas irradiaciones láser sin agregado de peróxido de hidrógeno. } \\
\hline 3 & Pura & No & 10 seg & $\begin{array}{c}\text { lW - lJ continua } \\
\text { fibra } 400\end{array}$ & $3 \mathrm{~min}$ & Pura \\
\hline 4 & Pura & No & 10 seg & $\begin{array}{l}1 \mathrm{~W}-1 \mathrm{~J} \text { continua } \\
\text { fibra } 600\end{array}$ & $3 \mathrm{~min}$ & Pura \\
\hline 5 & Pura & No & 10 seg & $\begin{array}{c}2,5 \mathrm{~W}-1,2 \mathrm{~J}-50 \mathrm{~Hz} \\
(1 / 1)-\text { fibra } \\
600 \mu \mathrm{m}\end{array}$ & $3 \mathrm{~min}$ & Pura \\
\hline \multicolumn{7}{|c|}{ Los tubos 6, 7, 8, 9 y 10 fueron adicionados con peróxido de hidrógeno siguiendo el protocolo del Dr. Rey. } \\
\hline 6 & Pura & Sí +1/3 & 10 seg & $\begin{array}{c}2,5 \mathrm{~W}-1,2 \mathrm{~J}-50 \mathrm{~Hz} \\
(1 / 1)-\text { fibra } \\
600 \mu \mathrm{m}\end{array}$ & $3 \mathrm{~min}$ & $10^{-5}$ \\
\hline 7 & Pura & Sí +1/3 & $10 \mathrm{seg}$ & $\begin{array}{c}2 \mathrm{~W}-1 \mathrm{~J}-50 \mathrm{~Hz} \\
(1 / 1)-\text { fibra } \\
600 \mu \mathrm{m}\end{array}$ & $3 \mathrm{~min}$ & $10^{-5}$ \\
\hline 8 & Pura & Sí + l/3 & 15 seg & $\begin{array}{l}1 \mathrm{~W}-0,5 \mathrm{~J}-50 \mathrm{~Hz} \\
(1 / 1)-\text { fibra } \\
600 \mu \mathrm{m}\end{array}$ & $3 \mathrm{~min}$ & $10^{-5}$ \\
\hline 9 & Pura & Sí + l/3 & 20 seg & $\begin{array}{c}0,6 \mathrm{~W}-0,3 \mathrm{~J}-50 \mathrm{~Hz} \\
(1 / 1)-\text { fibra } \\
400 \mu \mathrm{m}\end{array}$ & $3 \mathrm{~min}$ & $10^{-6}$ \\
\hline 10 & Pura & Sí +1/3 & 15 seg & $\begin{array}{c}4 \mathrm{~W}-2 \mathrm{~J}-500 \mathrm{~Hz} \\
(1 / 1)-\text { fibra } \\
600 \mu \mathrm{m}\end{array}$ & $3 \mathrm{~min}$ & $10^{-6}$ \\
\hline
\end{tabular}

Pura: Aproximadamente 2.000.000.

$10^{-1}$ : Aproximadamente 200.000, disminución del 90\%.

10-2: Aproximadamente 20.000, disminución del 99\%.

$10^{-3}$ : Entre 500 y 2.000 , disminución del $99,95 \%$.
10-4: Entre 100 y 500, disminución del 99,987\%

$10^{-5}$ : Entre 10 y 20 , disminución del $99,999 \%$.

$10^{-6}$ : Entre 1 y 10 . 


\begin{tabular}{|c|c|c|c|c|c|c|}
\hline \multicolumn{7}{|c|}{ TABLA 2.- TEST SOBRE PEPTOSTREPTOCOCCUS MICRON } \\
\hline Tubo & $\begin{array}{l}\text { Cultivo } \\
\text { inicial }\end{array}$ & $\begin{array}{c}\mathrm{H}_{2} \mathrm{O}_{2} \\
3 \%\end{array}$ & $\begin{array}{c}\text { Esposición } \\
\text { láser de diodo } \\
810 \mu \mathrm{m}\end{array}$ & $\begin{array}{l}\text { Regulación } \\
\text { láser }\end{array}$ & $\begin{array}{c}\text { Tiempos } \\
\text { totales }\end{array}$ & $\begin{array}{c}\text { Cultivo } \\
\text { final }\end{array}$ \\
\hline 1 & Pura & No & No & $\begin{array}{l}\text { Tubo de estudio } \\
\text { cultivo fin de la } \\
\text { experiencia }\end{array}$ & $40 \mathrm{~min}$ & Pura \\
\hline \multicolumn{7}{|c|}{ El tubo 2 ha sido adicionado con 1/3 de peróxido de hidrógeno sin irradiación láser. } \\
\hline 2 & Pura & $3 \min +1 / 3$ & No & & $3 \mathrm{~min}$ & $10^{-1}$ \\
\hline \multicolumn{7}{|c|}{ Los tubos 3, 4 y 5 fueron expuestos a distintas irradiaciones láser sin agregado de peróxido de hidrógeno. } \\
\hline 3 & Pura & No & $10 \mathrm{seg}$ & $\begin{array}{c}\text { lW - lJ continua } \\
\text { fibra } 400\end{array}$ & $3 \mathrm{~min}$ & Pura \\
\hline 4 & Pura & No & $10 \mathrm{seg}$ & $\begin{array}{l}\text { lW - 1J continua } \\
\text { fibra } 600\end{array}$ & $3 \mathrm{~min}$ & Pura \\
\hline 5 & Pura & No & $10 \mathrm{seg}$ & $\begin{array}{c}2,5 \mathrm{~W}-1,2 \mathrm{~J}-50 \mathrm{~Hz} \\
(1 / 1)-\text { fibra } \\
600 \mu \mathrm{m}\end{array}$ & $3 \mathrm{~min}$ & Pura \\
\hline \multicolumn{7}{|c|}{ Los tubos 6, 7, 8, 9 y 10 fueron utilizados con peróxido de hidrógeno siguiendo el protocolo del Dr. Rey. } \\
\hline 6 & Pura & Sí + l/3 & 10 seg & $\begin{array}{c}2,5 \mathrm{~W}-1,2 \mathrm{~J}-50 \mathrm{~Hz} \\
(1 / 1)-\text { fibra } \\
600 \mu \mathrm{m}\end{array}$ & $3 \mathrm{~min}$ & $10^{-2}$ \\
\hline 7 & Pura & Sí $+1 / 3$ & 10 seg & $\begin{array}{c}2 \mathrm{~W}-1 \mathrm{~J}-50 \mathrm{~Hz} \\
(1 / 1)-\text { fibra } \\
600 \mu \mathrm{m}\end{array}$ & $3 \mathrm{~min}$ & $10^{-2}$ \\
\hline 8 & Pura & Sí + l/3 & $15 \mathrm{seg}$ & $\begin{array}{c}1 \mathrm{~W}-0,5 \mathrm{~J}-50 \mathrm{~Hz} \\
(1 / 1)-\text { fibra } \\
600 \mu \mathrm{m}\end{array}$ & $3 \mathrm{~min}$ & $10^{-2}$ \\
\hline 9 & Pura & Sí + l/3 & 20 seg & $\begin{array}{c}0,6 \mathrm{~W}-0,3 \mathrm{~J}-50 \mathrm{~Hz} \\
(1 / 1)-\text { fibra } \\
400 \mu \mathrm{m}\end{array}$ & $3 \mathrm{~min}$ & $10^{-2}$ \\
\hline 10 & Pura & Sí $+1 / 3$ & $15 \mathrm{seg}$ & $\begin{array}{c}4 \mathrm{~W}-2 \mathrm{~J}-500 \mathrm{~Hz} \\
(1 / 1)-\text { fibra } \\
600 \mu \mathrm{m}\end{array}$ & $3 \mathrm{~min}$ & $10^{-3}$ \\
\hline
\end{tabular}

Pura: Aproximadamente 2.000.000.

$10^{-1}$ : Aproximadamente 200.000, disminución del 90\%.

10-2: Aproximadamente 20.000, disminución del 99\%.

10-3: Entre 500 y 2.000 , disminución del $99,95 \%$.

$10^{-4}$ : Entre 100 y 500, disminución del $99,987 \%$

$10^{-5}$ : Entre 10 y 20, disminución del $99,999 \%$.

10-6: Entre 1 y 10 . 


\begin{tabular}{|c|c|c|c|c|c|c|}
\hline \multicolumn{7}{|c|}{ TABLA 3.- TEST SOBRE PREVOTELLA INTERMEDIA } \\
\hline Tubo & $\begin{array}{l}\text { Cultivo } \\
\text { inicial }\end{array}$ & $\begin{array}{c}\mathrm{H}_{2} \mathrm{O}_{2} \\
3 \%\end{array}$ & $\begin{array}{c}\text { Esposición } \\
\text { láser de diodo } \\
810 \mu \mathrm{m}\end{array}$ & $\begin{array}{c}\text { Regulación } \\
\text { láser }\end{array}$ & $\begin{array}{c}\text { Tiempos } \\
\text { totales }\end{array}$ & $\begin{array}{c}\text { Cultivo } \\
\text { final }\end{array}$ \\
\hline 1 & Pura & No & No & $\begin{array}{c}\text { Tubo de estudio } \\
\text { cultivo fin de la } \\
\text { experiencia }\end{array}$ & $40 \mathrm{~min}$ & Pura \\
\hline \multicolumn{7}{|c|}{ El tubo 2 ha sido adicionado con $1 / 3$ de peróxido de hidrógeno sin irradiación láser. } \\
\hline 2 & Pura & $3 \min +1 / 3$ & No & & $3 \mathrm{~min}$ & $10^{-5}$ \\
\hline \multicolumn{7}{|c|}{ Los tubos 3, 4 y 5 fueron expuestos a distintas irradiaciones láser sin agregado de peróxido de hidrógeno. } \\
\hline 3 & Pura & No & $10 \mathrm{seg}$ & $\begin{array}{c}1 \mathrm{~W}-1 \mathrm{~J} \text { continua } \\
\text { fibra } 400\end{array}$ & $3 \mathrm{~min}$ & Pura \\
\hline 4 & Pura & No & $10 \mathrm{seg}$ & $\begin{array}{l}\text { 1W - 1J continua } \\
\text { fibra } 600\end{array}$ & $3 \mathrm{~min}$ & Pura \\
\hline 5 & Pura & No & 10 seg & $\begin{array}{c}2,5 \mathrm{~W}-1,2 \mathrm{~J}-50 \mathrm{~Hz} \\
(1 / 1)-\text { fibra } \\
600 \mu \mathrm{m}\end{array}$ & $3 \mathrm{~min}$ & $10^{-1}$ \\
\hline \multicolumn{7}{|c|}{ Los tubos 6, 7, 8, 9 y 10 fueron utilizados con peróxido de hidrógeno siguiendo el protocolo del Dr. Rey. } \\
\hline 6 & Pura & Sí $+1 / 3$ & 10 seg & $\begin{array}{c}2,5 \mathrm{~W}-1,2 \mathrm{~J}-50 \mathrm{~Hz} \\
(1 / 1)-\text { fibra } \\
600 \mu \mathrm{m}\end{array}$ & $3 \mathrm{~min}$ & $10^{-6}$ \\
\hline 7 & Pura & Sí + 1/3 & $10 \mathrm{seg}$ & $\begin{array}{c}2 \mathrm{~W}-1 \mathrm{~J}-50 \mathrm{~Hz} \\
(1 / 1)-\text { fibra } \\
600 \mu \mathrm{m}\end{array}$ & $3 \mathrm{~min}$ & $10^{-6}$ \\
\hline 8 & Pura & Sí + 1/3 & $15 \mathrm{seg}$ & $\begin{array}{c}1 \mathrm{~W}-0,5 \mathrm{~J}-50 \mathrm{~Hz} \\
(1 / 1)-\text { fibra } \\
600 \mu \mathrm{m}\end{array}$ & $3 \mathrm{~min}$ & $10^{-6}$ \\
\hline 9 & Pura & Sí + 1/3 & 20 seg & $\begin{array}{c}0,6 \mathrm{~W}-0,3 \mathrm{~J}-50 \mathrm{~Hz} \\
(1 / 1)-\text { fibra } \\
400 \mu \mathrm{m}\end{array}$ & $3 \mathrm{~min}$ & $10^{-6}$ \\
\hline 10 & Pura & Sí + 1/3 & $15 \mathrm{seg}$ & $\begin{array}{c}\text { 4W-2J-500Hz } \\
(1 / 1)-\text { fibra } \\
600 \mu \mathrm{m}\end{array}$ & $3 \mathrm{~min}$ & $10^{-6}$ \\
\hline
\end{tabular}

Pura: Aproximadamente 2.000.000.

$10^{-1}$ : Aproximadamente 200.000, disminución del 90\%.

$10^{-2}$ : Aproximadamente 20.000, disminución del 99\%.

$10^{-3}$ : Entre 500 y 2.000 , disminución del $99,95 \%$.

$10^{-4}$ : Entre 100 y 500, disminución del $99,987 \%$

$10^{-5}$ : Entre 10 y 20 , disminución del 99,999\%.

$10^{-6}$ : Entre 1 y 10 . 


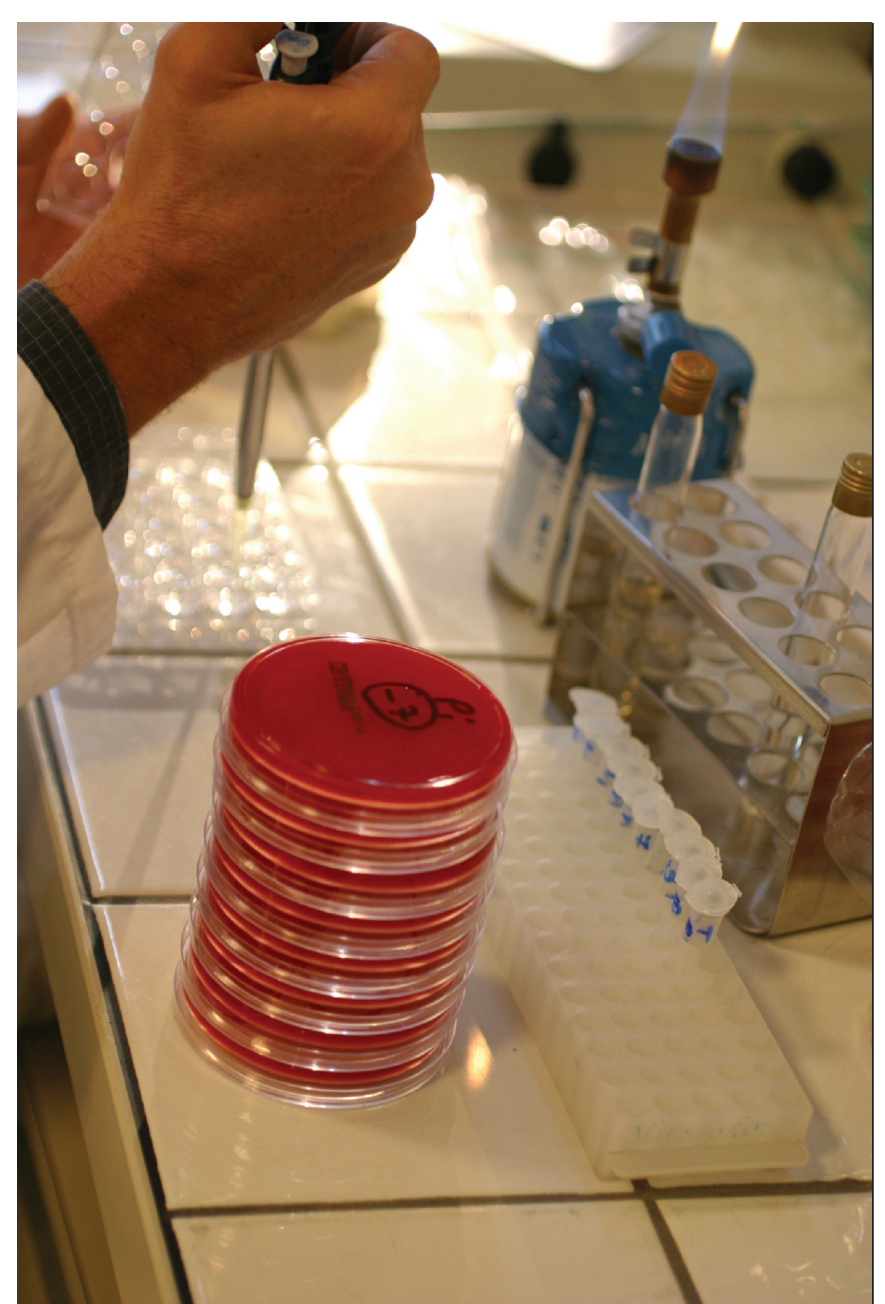

Fig.4.

revelado una disminución poco significativa. La asociación de los dos tratamientos ha potenciado su acción bactericida llevando a una disminución significativa de las colonias bacterianas.

\section{CONCLUSIONES}

Los test microbiológicos han demostrado la plena eficiencia de la asociación láser - agua oxigenada sobre todas las especies bacterianas citadas precedentemente. Los cultivos microbiológicos efectuados revelan como, no obstante el efecto bactericida, el láser tiene una escasa acción sobre las cepas bacterianas testadas si no es asociado al agua oxigenada. En particular en el caso de la Prevotella intermedia y del fusobacetrium nucleatum el empleo exclusivo agua oxigenada al 3\% ha dado resultados mejores respecto a la ex- clusiva irradiación láser, mientras que la asociación de los dos tratamientos ha siempre dado óptimos resultados. En el caso del Peptostreptococcus micron el empleo de agua oxigenada y del láser separadamente han dado una escasa disminución de la carga bacteriana mientras que la asociación de los tratamientos ha potenciado su acción bactericida.

\section{ABSTRACT}

Laser in odontology, thanks to its antibacterial capabilities, haemostatic and of minor operating symptomatology, finds a vast field of application within the framework of periodontal therapy.

In this study has been tested the effectiveness of a protocol that foresees the associated use of laser irradiation and hydrogen peroxide with the goal of reducing the bacterial charge of stocks commonly present in the active periodontal pockets and resistant to the bactericide action of laser irradiation alone such as Prevotella intermedia, Fusobacterium nucleatum, Peptostreptococcus micron.

The laboratory method used foresees the following protocol: each bacterial suspension has been exposed to hydrogen peroxide at $3 \%$ concentrations and it has been irradiated with laser for 10, 15 or 20 seconds, using sterile $1.5 \mathrm{ml}$ Eppendorf tubes.

The results confirm the higher bactericide effectiveness of the combined action of hydrogen peroxide and laser.

The microbiological cultivations carried out reveal how, in spite of the bactericide effect, the laser has an insufficient action on bacterial stocks tested if it isn't associated with hydrogen peroxide. Particularly in the case of the Prevotella intermedia or the Fusobacterium nucleatum the use of just hydrogen peroxide at $3 \%$ has offered better results than the laser irradiation alone while the association of both treatments has always offered optimal results. In the case of the Peptostreptococcus micron the use of hydrogen peroxide and laser separately has offered an insufficient reduction of the bacterial count while the association of treatments has increased their bactericide action.

\section{KEY WORDS}

Diode laser, bacteria, hydrogen peroxide. 


\section{RÉSUMÉ}

Le laser en odontostomatologie, pour ces propriétès antibacteriques, émostatiques et antalgiques, est bien utilizè en parodontologie.

Le but de cette récherche est de tester un protocol en vitro sur l'association du laser et de l'eau oxigénée, pour reduir les bacterias les plus résistents dans les poches parodontales, comme Prevotella intermedia, Fusobacterium nucleatum, Peptostreptococcus micros.

$30 \mu l$ de sospension bactérienne (en utilisand des eppendorf srérilesde $1,5 \mathrm{ml}$ ) a étè traitè avec l'eau oxigénée à $3 \%$, en irradiand avec le laser pour 5 ou $10,15,20$ seconds.

Les résultats confirment l'éfficacité de cette combination eau oxigénée/laser sur touts les trois bacterias.

Particulierement sur prevotella intermedia et fusobacterium nucleatum l'eau oxigénée à $3 \%$ est plus efficace que le laser tout seul, ainsi que pour le peptostreptococcus micron la seule association est éfficace.

\section{AGRADECIMIENTOS}

Un particular agradecimiento al Dr. Marcos José Maggiani por su importante contributo científica y de redacción.

\section{BIBLIOGRAFÍA}

1. Ando Y, Aoki A, Watanabe H, Ishikawa I. Bactericidal effect of erbium YAG laser on periodontopathic bacteria. Lasers Surg Med 1996;19(2):190-200.

2. Ben Hatit $\mathrm{Y}$, Blum $\mathrm{R}$ et al. The effects af a pulsed Nd: YAG laser an subgingival bacterial flora and on cementum: an in vivo study. J Cl Laser Med Surg 1996; 14 : 137-43.

3. Blum JY, Michailesco P, Abadie MJM, An evaluation of bacterial effect of the Nd:YAG laser. J Endodont 1997;23 (9):583-5.
4. Cobb CM, McCawley TK, Killoy WJ. A preliminary study on the effects of the Nd:YAG laser on root surfaces and subgingival microflora in vivo. J Periodontol 1992; 63:701-7.

5. Folwaczny $M$, Liesenhoff $T$ Lehn $N$, Horch HH.Bactericidal action of 308nmexcimer-laser radiation: an in vivo investigation. J Endodont 1998 Dec;24(12):781-5.

6. Gold SI. Application of the Nd:YAG laser in periodontics. NY J Dent 1991;170:343-6.

7. Ito K, Nishikata J, Murai S. Effects of Nd:YAG laser radiation on removalof a root surface smear layer after root planing: a scanning electron microscopic study. J Periodontol 1993;64(6):547-52.

8. Rey G. Montpellier Bacteriologie bucco-dentaire et laser. 1999 Les bacteries a gram negatif \& les bacteries a gram positif. 2001 .

9. Rey G. Lápport du laser le traitament de poche parodontals. Implantodontie 2001.

10. Rey G. Results statique du traitament des maladies parodontales au laser. Implantodontie 2001.

11. Rochd T, CalasP, Roques C. Evaluation of the bactericidal activity on oral organism of the Nd:YAG laser in vitro. Laser Med Sci 1998, 13:288-92.

12. Tseng P, Gilkeson CF, Palmer J, Liew V. The bactericidal effect of a Nd:YAG laser in vitro. J Dent Res 1991;70 (Spec. Issue):650(Abstr.7).

13. White JM, Goodis HE, Cohen JN. Bacterial reduction of contaminated dentin by Nd:YAG laser. J Dent Res 1991;70(Spec. Issue):412(Abstr. 1170).

\section{CORRESPONDENCIA}

Dott. Gianluigi Caccianiga

Via Simoncini 20

24100 - Bergamo (BG)

Italy

e-mail: gianluigi.caccianiga@unimib.it 